\title{
Analiza wyników badań zmęczeniowych elementów stalowych w świetle wymogów norm europejskich
}

\author{
Analysis of fatigue tests results of steel elements \\ in the light of the requirements of European standards
}

\section{Streszczenie}

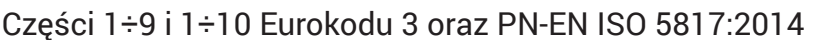
uporządkowały reguły projektowania konstrukcji stalowych narażonych na zmęczenie. Podane klasy zmęczeniowe FAT określono wg jednakowego algorytmu dla badanych elementów poziomu jakości B i C. W artykule wykazano, że algorytmu tego nie można stosować dla elementów starzonych oraz z niezgodnościami spawalniczymi, karbami poziomu jakości D i większymi. Wymagania dotyczące zmęczenia z części 1 $\div 9$ Eurokodu 3, podobnie jak udarności z części $1 \div 10$, nie powinny dotyczyć konstrukcji eksploatowanych.

Słowa kluczowe: zmęczenie; karb; procesy starzeniowe

\section{Abstract}

Parts $1 \div 9$ and $1 \div 10$ of the Eurocode 3 and the PN-EN ISO 5817: 2014 standard ordered the rules for designing steel structures exposed to fatigue. The given FAT fatigue classes were determined according to the same algorithm for the tested quality level elements B and C. The article shows that this algorithm can not be used for aging elements and with welding incompatibilities, notches of quality level $D$ and larger. Fatigue requirements from parts $1 \div 9$ of Eurocode 3 , as well as impact strengths from parts $1 \div 10$, should not apply to exploited structures.

Keywords: fatigue; testing; notch; aging processes

\section{Wstęp}

W przypadku spawania na wytrzymałość zmęczeniową mają wpływ różne czynniki, których całościowe uwzględnienie jest możliwe wyłącznie w eksperymentalnych badaniach. Takie rozwiązanie ma jedną zasadniczą wadę - jest najdroższe. Poszukiwane są inne, nowe rozwiązania do oceny trwałości konstrukcji, omówione w $[1 \div 3]$.

Ogólne wytyczne badań metali na zmęczenie w przypadku osiowego rozciągania i sposób przedstawiania wyników prób określała $\mathrm{PN}-76 / \mathrm{H}-04325$ [4], która straciła ważność 10 listopada 2011 r. Według tej normy badania należy zaczynać od najwyższego poziomu naprężeń, przy którym nastąpi zniszczenie próbek po ok. $10^{4}$ cyklach, a następnie obniżać poziomy naprężeń aż do momentu, w którym badane próbki nie ulegną zniszczeniu przy $\mathrm{N}=2 \cdot 10^{6}$ cyklach. Liczba poziomów naprężeń nie może być niższa od 5, a liczba próbek na poziomie nie mniejsza niż 3 sztuki. Wyniki badań przedstawia się graficznie za pomocą wykresów Wöhlera, Smitha i Heigha.

Autorzy artykułu wszystkie badania zmęczeniowe prowadzili przy tętniącym rozciąganiu i współczynniku asymetrii cyklu $R=0,1$ (rys. 1). Badania prowadzono na pulsatorze z częstotliwością 300 cykli na minutę. Na podstawie analizy

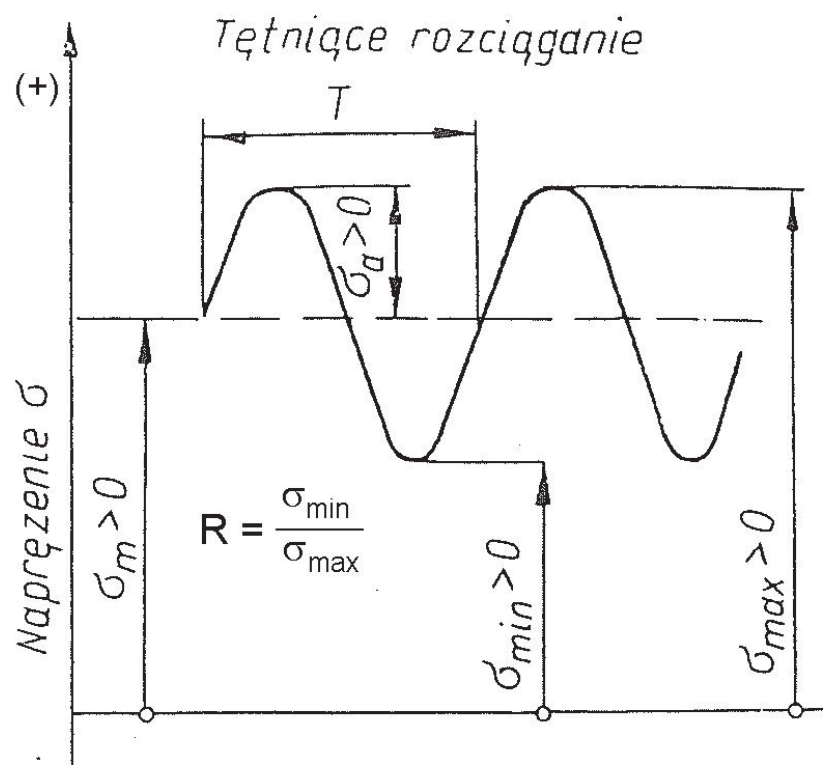

Rys. 1. Przyjęty cykl naprężeń

Fig. 1. The adopted cycle of stresses

Dr hab. inż. Bernard Wichtowski, em. prof. ZUT; dr inż. Marek Wichtowski- Zachodniopomorski Uniwersytet Technologiczny w Szczecinie

Autor korespondencyjny/Corresponding author: marekw@zut.edu.pl 
statystycznej wyników badań próbek zniszczonych (rys. 2), metodą najmniejszych kwadratów, opracowano równanie prostej regresji w układzie logarytmicznym. Uzyskano bardzo zróżnicowane wartości nieograniczonej wytrzymałości zmęczeniowej (WNWZ) - $Z_{\mathrm{rj}}$ w porównaniu z wartościami FAT $\left(\Delta \sigma_{c}\right)$ określonymi wg algorytmu zalecanego przez Eurokod 3 [5].

Uwzględniając nowe zalecenia wytrzymałości zmęczeniowej dla niezgodności spawalniczych (NS) poziomu jakości B i C [6] oraz zalecenia Europejskiego Komitetu JRC i ECCS [7,8], w zakresie oceny trwałości zmęczeniowej istniejących mostów stalowych, zaistniałe zróżnicowanie wyników badań wymaga analizy wyjaśniającej. Artykuł jest kompilacją zagadnień wytrzymałości zmęczeniowej omówionej w 12 własnych publikacjach. Stanowi rekapitulację tam zawartych wniosków.

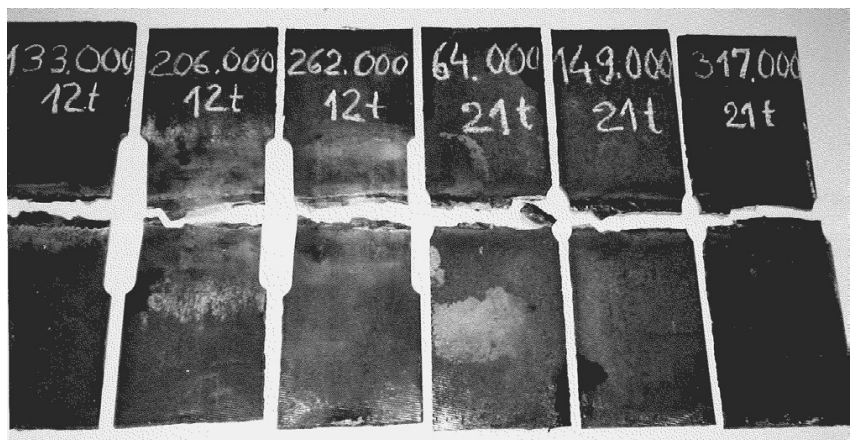

Rys. 2. Zniszczone próbki po badaniach zmęczeniowych

Fig. 2. Damaged samples after fatigue tests

\section{Własne badania weryfikacyjne}

W latach 1956-1990 Zakład Konstrukcji Metalowych Politechniki Szczecińskiej przeprowadził badania rentgenograficzne spoin czołowych w 155 mostach kolejowych [9]. Ogółem przebadano 15875 złączy spawanych. W 34 obiektach wykryto pęknięcia spoin w 437 złączach oraz stwierdzono 4123 rentgenogramy o poziomie jakości $D$ i o niezgodnościach spawalniczych większych od pj. D, tj. w $26 \%$ ogólnej liczby przebadanych złączy. Powtórne badania niektórych mostów w odstępach 5:8 letnich nie wykazały zmian lub powstania nowych pęknięć. W celu uzyskania częściowej odpowiedzi na pytanie: czy mogą zaistnieć takie okoliczności, które spowodują powstanie pęknięć, współautor (BW) podjął próbę wyznaczenia nieograniczonej wytrzymałości zmęczeniowej $\mathrm{Z}_{\mathrm{r} j}$ i oszacowania wpływu starzenia materiału na tę wytrzymałość.

Przeprowadzono badania zmęczeniowe stali gatunku St3SX o zróżnicowanym stopniu starzenia oraz czterech grup mostowych złączy doczołowych. Metodykę badań

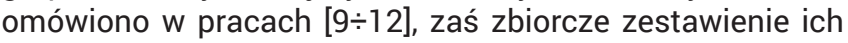
wyników przedstawiono w tablicy I i na rysunkach 3 i 4 . Określone tam proste regresji dotyczą badań zmęczeniowych:

a) na rysunku 3

- próbek PSS (a) - stali starzonej samorzutnie w okresie 35 lat, dla których wartość nieograniczonej wytrzymałości zmęczeniowej (WNWZ) wynosi Zrj = 145,3 MPa;

- próbek PDS (b) - stali starzonej samorzutnie w okresie 35 lat i dodatkowo poddanej starzeniu przyspieszonemu, o uzyskanej WNWZ $-Z_{\mathrm{rj}}=157,3 \mathrm{MPa}$.

b) na rysunku 4

- próbek a - ze spoinami czołowymi zestarzonymi samorzutnie $\mathrm{w}$ okresie 45 lat, dla których WNWZ wynosi $Z_{\text {rj }}=101,4 \mathrm{MPa}$;
- próbek b - ze spoinami czołowymi poziomu jakości B+, B i C, dla których WNWZ wynosi $Z_{\mathrm{rj}}=125,3 \mathrm{MPa}$,

- próbek c - ze spoinami czołowymi z pęknięciami wewnętrznymi o uzyskanej z badań WNWZ równej $Z_{\mathrm{rj}}=89,9 \mathrm{MPa}$,

- próbek d - ze spoinami czołowymi przykrytymi jednostronnymi nakładkami rombowymi o WNWZ $\mathrm{Z}_{\mathrm{rj}}=72,2 \mathrm{MPa}$.

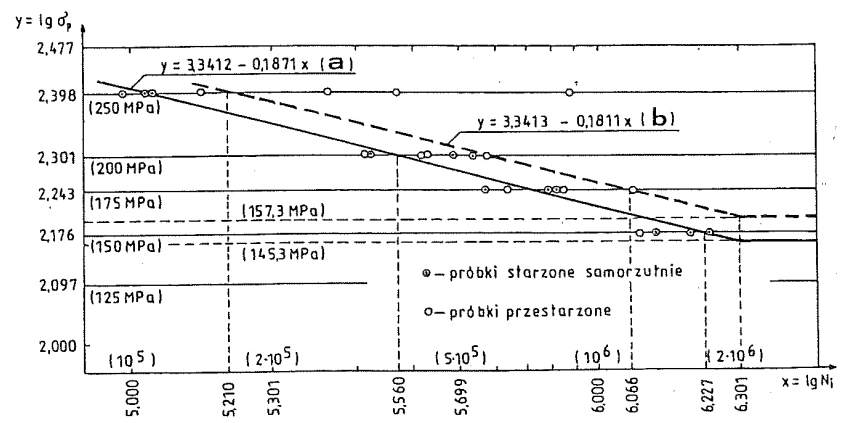

Rys. 3. Proste regresji z badań: (a) stali starzonej samorzutnie, (b) stali przestarzonej

Fig. 3. Regression lines from tests of: (a) spontaneous aged steel, (b) overaged steel

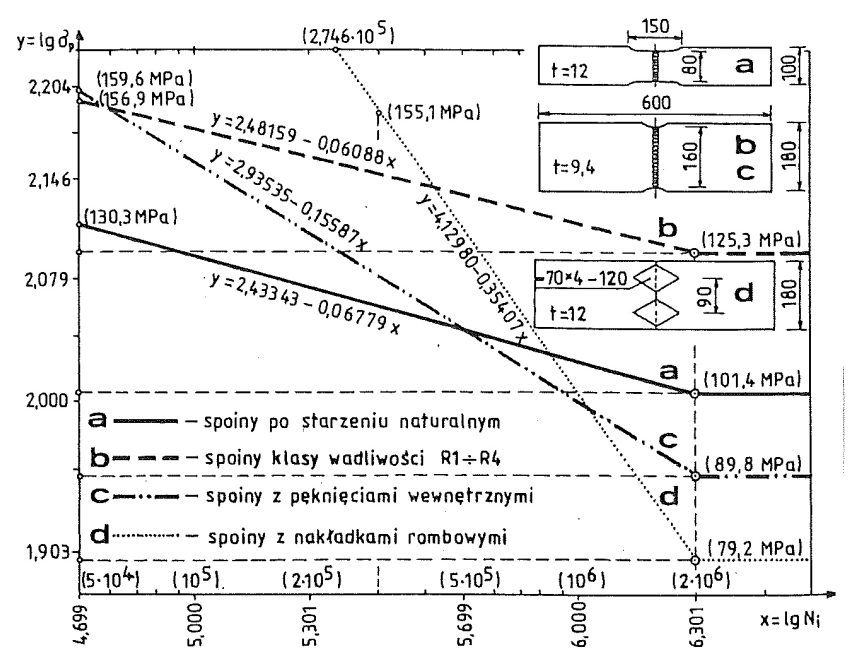

Rys. 4. Zestawienie prostych regresji badanych czterech rodzajów złączy ze spoinami czołowymi

Fig. 4. Specification of regression lines of four tested types of joints with butt welds

Podana w kolumnie 7 tablicy I wartość tzw. współczynnika korelacji liniowej $r$ stanowi kryterium potwierdzające liniową zależność pomiędzy wielkościami x i y (rys. 3 i 4). Jego wartość zmienia się w granicach od $| \pm 1|$ do 0 . Gdy $|r|=1$, to dopasowanie jest idealne, wszystkie punkty pomiarowe leżą na prostej. Gdy $r=0$, to zależność liniowa pomiędzy x i y nie istnieje. Wzór na współczynnik korelacji ma postać:

$$
r=\frac{n \sum_{i=1}^{n} x_{i} y_{i}-\sum_{i=1}^{n} x_{i} \sum_{i=1}^{n} y_{i}}{\sqrt{\left[\sum_{i=1}^{n} x_{i}^{2}-\left(\sum_{i=1}^{n} x_{i}\right)^{2}\right] \cdot\left[n \sum_{i=1}^{n} y_{i}^{2}-\left(\sum_{i=1}^{n} y_{i}\right)^{2}\right]}},
$$

gdzie: i = 1,2,3,...n; czyli n jest ilością par punktów $\left(x_{i}, y_{i}\right)$.

Najniższe wartości współczynnika korelacji uzyskano w przypadku próbek stali przestarzonej PDS (b) i próbek a ze spoinami czołowymi z konstrukcji estakady suwniczej eksploatowanej (starzonej) przez 45 lat. Wartości te wynoszą odpowiednio $r=-0,681$ i -0,590. Ich mała wartość świadczy o dużym rozrzucie uzyskanych wyników z poszczególnych badanych próbek. Jest to wynik zaskakujący w odniesieniu do próbek (b) ze stali przestarzonej (PDS), próbek bez koncentratorów naprężeń w postaci niezgodności spawalniczych. Natomiast wszystkie próbki a miały niezgodności 
Tablica I. Charakterystyka badań zmęczeniowych 6 rodzajów próbek

Table I. Characteristics of fatigue tests of 6 types of samples

\begin{tabular}{|c|c|c|c|c|c|c|}
\hline \multirow{2}{*}{$\begin{array}{l}\text { Rodzaj } \\
\text { próbki }\end{array}$} & \multirow{2}{*}{$\begin{array}{c}\text { Liczba próbek } \\
\text { zniszczonych, } \\
\text { (niezniszcz.) }\end{array}$} & \multirow{2}{*}{$\begin{array}{c}\text { Liczba } \\
\text { poziomów } \\
\text { naprężeń }\end{array}$} & \multirow{2}{*}{$\sigma_{\max }{ }^{1)}, \mathrm{MPa}$} & \multicolumn{2}{|c|}{ Zakres liczby cykli N } & \multirow{2}{*}{$\begin{array}{l}\text { Współczynnik } \\
\text { korelacji }{ }^{2)}(-r)\end{array}$} \\
\hline & & & & próbki zniszczone & próbki niezniszczone & \\
\hline PSS (a) & $14(2)$ & 5 & $125,150,175,200,250$ & 1711000,97000 & 3254000,2937000 & 0,983 \\
\hline PDS (b) & $14(2)$ & 4 & $150,175,200,250$ & 1226000,142000 & 3290000,3000000 & 0,681 \\
\hline a & $7(1)$ & 4 & $85,95,105,115$ & 2035000,102800 & 3230000 & 0,590 \\
\hline b & $15(5)$ & 5 & $100,120,130,140,160$ & 1765000,30000 & 3283000,3000000 & 0,760 \\
\hline c & $18(3)$ & 6 & $50,80,100,120,130,140$ & 2678000,64000 & 3964000,3266000 & 0,782 \\
\hline d & $16(3)$ & 5 & $75,80,100,120,140$ & 1990200,386000 & 2391000,2330000 & 0,873 \\
\hline
\end{tabular}

spawalnicze poziomu jakości > D, typu przyklejenia międzywarstwowego oraz braku przetopu i w dwóch przypadkach pęknięcia technologiczne o długości 15 i $32 \mathrm{~mm}$.

W wyniku dodatkowego starzenia stali PDS dla próbek (b) nastąpił wyjątkowo duży wzrost jej granicy plastyczności $R_{e}$ o $86 \%$, a wytrzymałości $R_{m}$ o $26 \%$. Pomimo zaistniałych zmian właściwości materiałowych oraz zróżnicowanych wartości współczynników $r=-0,983$ i -0,681, dla próbek (a) i (b), uzyskano z badań mało zróżnicowane wartości wytrzymałości zmęczeniowej $Z_{\mathrm{rj}}=157 \mathrm{i} 145 \mathrm{MPa}$ (por. rys. 3). Wartości te są porównywalne $z$ kategoriami zmęczeniowymi $\Delta \sigma_{c}$ podanymi w normie [5], dla tego typu próbek. Są to: wyroby walcowane i ciągnione (karby 1, 2 i 3) oraz blachy cięte mechanicznie lub gazowo (karby 4 i 5), dla których $\Delta \sigma_{c}=160 \div 125 \mathrm{MPa}$.

\section{Wymagania zmęczeniowe wg norm europejskich}

W normie PN-EN 1993-1-9 [5] wytrzymałość zmęczeniowa jest zdefiniowana dla naprężeń normalnych za pomocą szeregu krzywych $\log \Delta \sigma_{R}-\log N$, z których każda odnosi się do określonej kategorii karbu. Każda kategoria karbu jest oznaczona za pomocą liczby mianowanej w MPa, która reprezentuje wartość odniesienia $\Delta \sigma_{c}$, tj. wytrzymałość zmęczeniową normatywną (kategoria zmęczeniowa) przy $2 \mathrm{mln}$ cykli (rys. 3 i 4). Krzywe wytrzymałości zmęczeniowej dla nominalnych naprężeń normalnych są zdefiniowane następująco:

$$
\log N=\log a-m \log \Delta \sigma_{R}
$$

gdzie:

$\mathrm{N}$ - liczba cykli obciążenia;

m - stała nachylenia krzywej zmęczeniowej, równa 3 lub 5; loga - stała, stowarzyszona z wielkością nachylenia i kategorią karbu.

W normie podano kategorie karbu, jakie należy przypisać różnym szczegółom konstrukcyjnym elementów o przekroju otwartym i rurowym. Z opisu tych kategorii wynika, że $w$ odniesieniu dla złączy doczołowych są to spoiny poziomu jakości B, wg PN-EN ISO 5817 [6]. Przyjmowanie tych kategorii w projektowaniu zalecał ECCS już w latach osiemdziesiątych XX wieku [14].

Nowa norma PN-EN ISO 5817 z 2014 r. zawiera dodatkowy Załącznik C (informacyjny), w którym podano wymagania dotyczące spoin w stali narażonej na zmęczenie. Podanowymaganiawprzypadkupoziomówjakościspełniających kryteria klasy zmęczenia (FAT). Wartość klasy zmęczenia FAT to zakres zmienności naprężeń $\Delta \sigma_{\mathrm{c}}$ W odniesieniu do 2-milionowej liczby cykli $\mathrm{N}_{\mathrm{c}}$ ustalonej przy $75 \%$ granicy tolerancji ufności średniej z 95\% prawdopodobieństwem przetrwania, z uwzględnieniem odchylenia standardowego, wielkości próby oraz wpływu naprężeń własnych. W analizie uwzględniono liczbę prób (nie mniejszą niż 10). W odniesieniu do spoin jakości C i B, zalecanych w mostach klasy wykonania EXC2 i EXC3, podano odpowiednie klasy zmęczenia FAT.

Analizę jakości spoin w funkcji klas zmęczenia wg powyższych norm i badań weryfikacyjnych przedstawiono w [15]. W Załączniku krajowym z 2010 r. do normy [5] zamieszczono postanowienie o treści: „Przy wyznaczeniu wytrzymałości zmęczeniowej na podstawie badań stosuje się zasady określone w 7.1 (3)", czyli wykorzystując wyniki badań weryfikacyjnych należy określić klasę FAT zgodnie z wymogami normowymi. Niestety Eurokod 3 nie podaje metodyki postępowania przy wyznaczaniu klasy FAT. Według rozeznania autorów algorytm określania normowej kategorii karbu $\Delta \sigma_{\mathrm{c}}$ podaje norma czeska ČSN 731401 [16] z roku 1998 i norma brytyjska BS ISO 12107 [17] z 2003 r. (II wydanie z 2016 r.).

\section{Wyznaczanie kategorii karbu $\Delta \sigma_{\mathrm{c}}$ według ČSN 731401}

Postępując wg schematu podanego na rysunku 5:

a) Wyznacza się prostą regresji przy prawdopodobieństwie uszkodzenia $50 \%$ z równania:

w którym:

$$
x=\alpha+\beta y,
$$

$$
\begin{gathered}
\alpha=\frac{\sum x_{i}-\beta \sum y_{i}}{n}, \quad \beta=\frac{S_{x y}}{S_{y y}}, \\
S_{x x}=\sum\left(x_{i}\right)^{2}-\frac{\left(\sum x_{i}\right)^{2}}{n}, \\
S_{y y}=\sum\left(y_{i}\right)^{2}-\frac{\left(\sum y_{i}\right)^{2}}{n}, \\
S_{x y}=\sum\left(x_{i} y_{i}\right)-\frac{\left(\sum x_{i}\right)\left(\sum y_{i}\right)}{n}
\end{gathered}
$$

Przyjmując zmienne niezależne $x_{i}$ i $y_{i}$ przy $n$ zniszczonych próbek wg tablicy l, otrzymuje się wartości $S_{x x}, S_{y y}$ i $S_{x y}$ oraz określa się równanie (3).

b) Na prostej regresji (3) przy $\mathrm{N}=2 \cdot 10^{6}$ cykli określa się zakres zmienności napreżeń:

$$
\Delta \sigma_{P}=\left(\frac{2 \cdot 10^{6}}{10^{\alpha}}\right)^{1 / \beta}
$$


c) Uwzględniając obliczoną amplitudę naprężeń $\Delta \sigma_{\mathrm{p}}$ na prostej regresji przy 95-procentowym prawdopodobieństwie trwałości wyznacza się liczbę cykli obciążenia $\mathrm{N}_{\mathrm{p}}$ :

gdzie:

$$
\log N_{P}=\log \left(2 \cdot 10^{6}\right)-t \cdot S_{R} \sqrt{f}
$$

$\mathrm{t}$ - wartość krytyczna rozkładu Studenta $\mathrm{t}(\mathrm{v}, \mathrm{y})$ przy stopniu swobody $v=n-2$ i poziomie istotności $y=0,05$,

$\mathrm{S}_{\mathrm{R}}$ - odchylenie standardowe oraz f określone są odpowiednio ze wzorów:

$$
S_{R}=\left[\frac{1}{n-2}\left(S_{x x}-\beta S_{x y}\right)\right]^{1 / 2}, \quad f=1+\frac{1}{n}+\frac{\left[\log \Delta \sigma_{P}-\frac{\sum y_{i}}{n}\right]^{2}}{S_{y y}},
$$

d) Oblicza się wytrzymałość zmęczeniową normatywną:

$$
\Delta \sigma_{C}=\Delta \sigma_{P}\left(\frac{2 \cdot 10^{6}}{N_{P}}\right)^{1 / \beta} \text {. }
$$

Postępując wg wyżej podanych zaleceń, określono klasy zmęczenia FAT o wartościach zamieszczonych w kolumnie 4 tablicy II oraz wyznaczono dla poszczególnych próbek wartości loga dla równań wytrzymałości zmęczeniowej (rys. 6 i 7) [12]. Jednocześnie dla pełnego zobrazowania

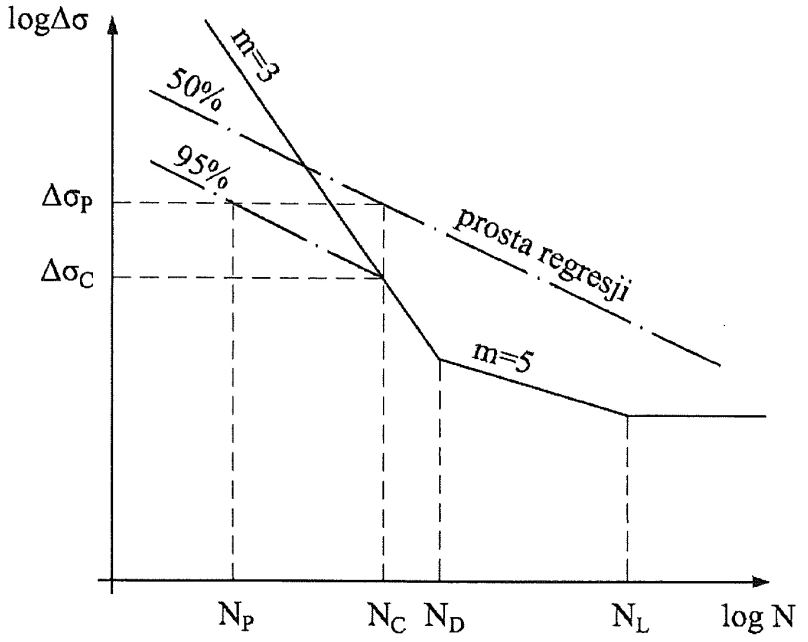

Rys. 5. Schemat postępowania przy wyznaczaniu kategorii karbu [16] Fig. 5. Procedure for the designation of the notch categories [16]

zagadnienia w tablicy II oraz na rysunku 6, podano także wartości FAT i loga dla pięciu typów karbów elementów stali, które są określone w normie [5].

\begin{tabular}{|c|c|c|c|c|c|}
\hline Szczegół konstrukcyjny & Rodzaj karbu & $z_{i j}$ & $\Delta \sigma_{\mathrm{c}}$ & $\Delta \sigma_{\mathrm{D}}$ & $\Delta \sigma_{\mathrm{L}}$ \\
\hline & PSS (a) & 145 & 118 & 86,9 & 47,7 \\
\hline & PDS (b) & 157 & 59 & 43,5 & 23,9 \\
\hline & $1,2,3$ & - & 160 & 117,9 & 64,8 \\
\hline & 4 & - & 140 & 103,2 & 56,7 \\
\hline & 5 & - & 125 & 92,1 & 50,6 \\
\hline & a & 101 & 38 & 28,0 & 15,4 \\
\hline & b & 125 & 80 & 58,9 & 32,4 \\
\hline & c & 90 & 45 & 33,1 & 18,2 \\
\hline & d & 79 & 28 & 20,6 & 11,3 \\
\hline
\end{tabular}

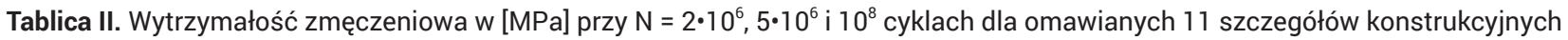
Table II. Fatigue strength in [MPa] at $\mathrm{N}=2 \cdot 10^{6}, 5 \cdot 10^{6}, 10^{8}$ cycles for the discussed 11 structural details 


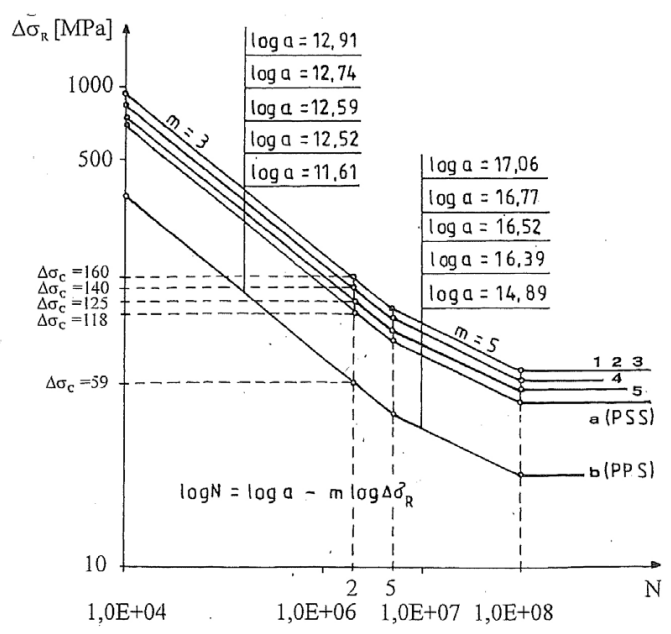

Rys. 6. Krzywe wytrzymałości zmęczeniowej (2) dla PSS i PPS oraz pięciu szczegółów normowych [5]

Fig. 6. Curves of fatigue strength (2) for PSS and PPS and five standard details [5]

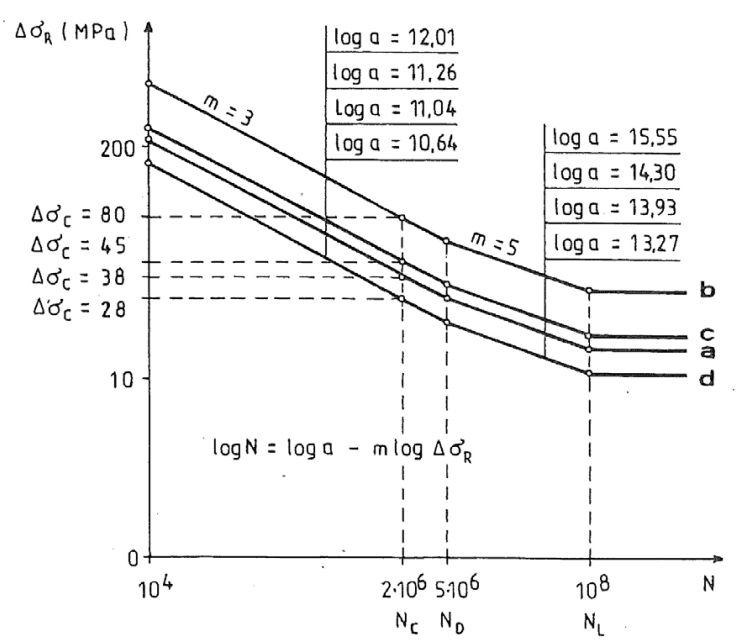

Rys. 7. Krzywe wytrzymałości zmęczeniowej (2) dla czterech rodzajów spoin czołowych

Fig. 7. Curves of fatigue strength (2) for four types of butt welds

\section{Wnioski}

Przedstawione badania stali starzonej oraz czterech typów spoin są zasadne, gdyż dotyczą wytrzymałości zmęczeniowej elementów (karbów) nieuwzględnionych w normie [5]. Duże zróżnicowanie uzyskanych wartości $\mathrm{Z}_{\mathrm{r} j}$, od 80 do $125 \mathrm{MPa}$, zostało spowodowane niejednakową strukturą stali oraz występującymi niezgodnościami spawalniczymi (NS) będącymi koncentratorami naprężeń. Zgodnie z rozwiązaniem C.E. Inglisa [1], naprężenie rozciągające $\sigma_{\mathrm{A}} \mathrm{W}$ wierzchołku koncentratora oblicza się ze wzoru:

$$
\sigma_{A}=\sigma_{z w}\left(1+2 \sqrt{\frac{t}{\rho}}\right)
$$

gdzie: $\sigma_{z w}$ - naprężenie zewnętrzne; $\mathrm{t}$ - 1/2 długości NS; $\rho$ - promień zaokrąglenia w dnie karbu.

Dokładne wartości $\sigma_{A}$ wywołane przez zróżnicowane typy NS w funkcji ich kształtu t/p i określone przez G. Najbiera [18], przeanalizowano w [9]. Według normy [6] klasy zmęczenia spoin czołowych FAT, ustalone przy $75 \%$ granicy tolerancji ufności z 95\% prawdopodobieństwem przetrwania, zamieszczone w normie [5] przyjęto wg badań IIW [19]. Są to spoiny sprawdzane metodami NDT, o poziomie jakości B i C, z NS wewnętrznymi w postaci pęcherzy i wtrąceń stałych. Praktycznie są to NS kuliste, dla których wartości naprężenia $\sigma_{\mathrm{A}}$ wynoszą $\sigma_{\mathrm{A}}=2,04 \sigma_{\mathrm{zw}}$, niezależnie od wielkości wady.

Zdaniem autorów, słusznie Eurokod 3 dla tego rodzaju spoin uporządkował reguły projektowania konstrukcji stalowych narażonych na zmęczenie. Są to zalecenia dla konstrukcji projektowanych, a nie dla konstrukcji eksploatowanych ze spoinami niekiedy poziomu jakości $\mathrm{D}$ i większymi od D; porównaj wartości $\Delta \sigma_{\mathrm{c}} \mathrm{W}$ tablicy II. Potwierdzeniem takiego rozumowania jest uwaga (3) w postanowieniach ogólnych normy [5] o brzmieniu: „Niniejsze reguły stosuje się do konstrukcji, których wykonanie jest zgodne z EN 1090". Zdaniem autorów, wzorem PN-EN 1993-1-10 należało również w normie PN-EN 1993-1-9 zaznaczyć, że wymogi zamieszczone nie dotyczą konstrukcji użytkowanych, o nieznanym poziomie jakości wg niezgodności spawalniczych i w indywidualnych badaniach nie należy stosować normowego określania kategorii zmęczeniowych. Bazować wówczas należy na wartościach $\mathrm{Z}_{\mathrm{rj}}$.

\section{Literatura}

[1] Neimitz A.: Mechanika pękania. PWN, Warszawa 1998.

[2] Szubryt M., Łukasik T.: Wytrzymałość zmęczeniowa konstrukcji spawanych - metody nowego podejścia, Biuletyn Instytutu Spawalnictwa w Gliwicach, $\mathrm{nr} 1 / 2008$.

[3] Wichtowski B.: Spawane złącza doczołowe w mostach kolejowych w świetle kryterium Przydatności Użytkowej Konstrukcji, Przegląd Spawalnictwa, nr 5/2016.

[4] PN-76/H-04325 Badanie metali na zmęczenie - Pojęcia podstawowe i ogólne wytyczne przygotowanie próbek oraz przeprowadzania prób.

[5] PN-EN ISO 1993-1-9: 2007 Eurokod 3: Projektowanie konstrukcji stalowych - Część 1-9: Zmęczenie.

[6] PN-EN ISO 5817: 2014 Spawanie - Złącza spawane ze stali, niklu, tytanu i ich stopów (z wyjątkiem spawanych wiązką - Poziomy jakości według niezgodności spawalniczych.

[7] Kühn B., et. al.: Assessment of existing steel structures: recommendation for estimation of remaining fatigue life. JRC Scientific and technical Report no. 43401, European Commison, Joint Research Centre, Luxempburg 2008.

[8] Wichtowski B.: Trwałość zmęczeniowa najstarszych spawanych mostów w Polsce w świetle badań, Przegląd Spawalnictwa, nr 5/2017.

[9] Wichtowski B.: Wytrzymałość zmęczeniowa spawanych złączy doczołowych w stalowych mostach kolejowych, PN PSz. nr 527, Wydawnictwo Politechniki Szczecińskiej, Szczecin 2002.
[10] Wichtowski B.: Wpływ starzenia stali na jej wytrzymałość zmęczeniową, Inżynieria i Budownictwo, nr 5/2009.

[11] Wichtowski B.: Kategorie zmęczeniowe spoin czołowych poprzecznych badanych laboratoryjnie, Inżynieria i Budownictwa, nr 5/2007.

[12] Wichtowski B.: Ocena zmęczenia i doboru stali na konstrukcje stalowych mostów spawanych wg Eurokodu 3, Przegląd Spawalnictwa, nr 12/2009.

[13] Szydłowski H. (red.): Teoria pomiarów, PWN, Warszawa 1981.

[14] Recommendations for the fatigue design of steel structures, First Edition, No 43, The European Convention for Constructional Steelwork, Lausanne 1985.

[15] Wichtowski B., Hołowaty J.: Jakość spoin czołowych w mostach w funkcji klas zmęczenia według norm europejskich i badań własnych, Inżyniera i Budownictwo, nr 9/2016.

[16] ČSN 731401: 1998 Navrhovani ocelovych konstrukci.

[17] BS ISO 12107: 2003 Metallic materials - Fatigue testing - Statistical planning and analysis of data.

[18] Najbier G.: Koncjentracija naprjażenij. Gostiechizdat, Moskwa 1947.

[19] Hobbacher A., Kassner M.: On Relation between Fatigue Properties of Welded Joints, Quality Criteria nad Groups in ISO 5817. IIW - document XIII - 2323-10. 